\title{
Repercussões das Redes Sociais na Subjetividade de Usuários: Uma Revisão Crítica da Literatura
}

\author{
Gabriel Artur Marra e Rosa ${ }^{1}$ \\ Faculdade de Psicologia e Psicopedagogia da Universidad del Salvador, \\ Buenos Aires, Argentina \\ Benedito Rodrigues dos Santos \\ Programa de Pós-Graduação Stricto Sensu em Psicologia da Universidade Católica \\ de Brasília, Brasília, DF, Brasil
}

\begin{abstract}
Resumo
Este artigo tem por objetivo mapear e revisar a literatura especializada sobre as repercussões das redes sociais na subjetividade de seus usuários, de modo a averiguar se essa literatura tem o potencial de elucidar os possíveis efeitos do processo denominado negociação de identidades na subjetividade dos indivíduos contemporâneos. Para a consecução desse objetivo, utilizou-se a metodologia do estado da arte, que verifica o status da produção acadêmica e científica sobre o tema. Acessaram-se quatro bases de dados durante o período de dois anos. A literatura constata a estetização do self, mas a interpreta como sociedade de consumo, limitando o entendimento de outras possibilidades interpretativas como um novo dispositivo de produção de sentidos. Assim, a conclusão a que se chegou é que, embora existam resultados relevantes, o campo dos estudos sobre esses efeitos apresenta algumas lacunas que precisam ser preenchidas para que se avance pelo próspero caminho virtual.
\end{abstract}

Palavras-chave: Redes sociais, repercussões, subjetividade, revisão de literatura.

\section{Repercussions of Social Networks on User Subjectivity: A Critical Literature Review}

\begin{abstract}
This article aims to map and review the literature on the repercussions of social networks on the subjectivity of its members to review whether such literature has the potential to elucidate the possible effects of the process called negotiation of identities in contemporary subjectivity of individuals. To achieve this goal, it was used the methodology of the state of the art, that checks the status of academic and scientific literature on the subject. Four data bases were accessed by a period of two years. The literature notes the aestheticization of the self, but interprets it as a consumer society, limiting the understanding of other interpretive possibilities as a new device for the production of meanings. Thus the conclusions reached is that although there are relevant results, the field of studies on these effects has some gaps that need to be filled in order to advance through the prosperous virtual path.
\end{abstract}

Keywords: Social networks, repercussions, subjectivity, literature review.

Endereço para correspondência: Superquadra Norte (SQN) 106, bloco "H”, Apto. 202, Brasília, DF, Brasil 70748-080. E-mail: gabriel_marra@hotmail.com e beneditos@ucb.br 


\section{Repercusiones de Redes Sociales en la Subjetividad de Usuarios: Una Revisión Crítica de Literatura}

\section{Resumen}

Este artículo tiene por objetivo mapear y revisar la literatura sobre repercusiones de las redes sociales en la subjetividad de sus usuarios para examinar si esta literatura tiene potencial para elucidar los posibles efectos del proceso llamado negociación de identidades en la subjetividad de los individuos contemporáneos. Para lograr este objetivo, se utilizó la metodología del estado del status del arte, que verifica el estado de la literatura académica y científica sobre el tema. Cuatro bases de datos fueron accedidas por un período de dos años. La literatura evidencia la estetización del self, pero la interpreta como sociedad de consumo, lo que limita la comprensión de otras posibilidades interpretativas como un nuevo dispositivo para la producción de sentidos. Por lo tanto, se concluye que, aunque existan resultados relevantes, el campo de los estudios sobre estos efectos aún posé brechas que necesitan ser llenadas para que se avance por el próspero camino de lo virtual.

Palabras clave: Redes sociales, repercusiones, subjetividad, revisión de literatura.

É notória a influência das redes sociais da internet no cotidiano de bilhões de pessoas, de empresas e de instituições de diferentes partes do mundo. O fenômeno dessas redes ou softwares sociais, somado às demais modalidades de comunidades on-line, tornou-se um dos maiores acontecimentos dos últimos anos, constituindo-se em uma nova modalidade de fazer sociedade (Lemos \& Lévy, 2010). Esse crescente interesse por essas redes também encontrou ressonância nos estudos acadêmicos. Nas últimas décadas, a Ciência das Redes, ou Science of Networks (Watts, 2004, 2007) desenvolveu-se e tornou-se um proeminente campo de estudos que congrega diferentes áreas do conhecimento.

A disseminação de pesquisas nesse âmbito iniciou-se com a prerrogativa de se analisar, por exemplo, a história e a modalidade de funcionamento dessas redes (Boyd \& Ellison, 2007) e culminou em pesquisas sobre o ethos comunicacional e interacional (Carrera, 2012), sobre a construção de identidades nas redes (Zhao, Grasmuck, \& Martin, 2008), sobre a conformação de grupos, sobre a proliferação de movimentos sociais mediante a utilização das redes (Bernardini \& Gobbi, 2013; Machado, 2007) e sobre os possíveis benefícios e danos que essas redes e os demais recursos disponíveis na internet podem causar aos seus usuários (Fortin \& Araújo, 2013; Kross, Verduyn, Demiralp, Park,
\& Lee, 2013). Esse ganho de institucionalidade acadêmica por parte desse assunto evidencia que o avanço nesse campo ocorreu de forma concomitante ao crescente interesse popular pelas redes sociais. De acordo com Lewis, Kaufman, Gonzalez, Wimmer e Christakis (2008), esse fenômeno alcançou o ápice com o surgimento de publicações e de conferências especializadas em redes sociais, tais como o periódico Social Networks e a The International Sunbelt Social Network Conference. Com efeito, esses avanços trouxeram, consigo, novos questionamentos a respeito de como o fenômeno das redes sociais pode repercutir na produção subjetiva em uma sociedade globalizada e conectada por meio da internet (Chou \& Edge, 2012; Raleiras, 2009).

$\mathrm{Na}$ atualidade, o uso das novas tecnologias digitais que, assim como as redes sociais, possuem a internet como epicentro, gerou uma forma específica de cultura que vem sendo denominada cibercultura. Em termos gerais, esse vocábulo pode ser definido como o conjunto de processos tecnológicos, midiáticos e sociais emergentes a partir da década de 1970, com a convergência das telecomunicações, da informática e da sociabilidade contracultural da época (Castells, 1999a). No contexto da chamada $\mathrm{ci}$ bercultura, o advento dos sites de redes sociais data do final da década de 1990. O SixDegrees é reconhecido como o site pioneiro dessas redes 
(Lemos \& Lévy, 2010). Nele, os usuários tiveram, pela primeira vez, a possibilidade de criar um perfil virtual que reunia registros de publicações e de contatos e viabilizava a navegação pelas redes sociais. Estas se constituíam por meio de utilizadores cadastrados nesse endereço eletrônico. Essas foram as características proclamadas por Boyd e Ellison (2007) como definidoras de rede social na internet.

No âmbito das pesquisas a respeito do $h a-$ bitus interacional dos usuários dessas redes, há certo consenso entre investigadores quanto ao fato de que, ao selecionar o que será exposto ou omitido sobre si mesmos, os usuários realizam um processo que tem sido denominado estetização do self (Carrera, 2012; Pinheiro, 2008; Zhao et al., 2008) ou negociação de identidades (Rosa \& Santos 2013). Esse processo se caracteriza pela exposição de gostos e de preferências culturais que refletem traços e características das identidades dos participantes. Essa exposição tende a ocorrer de acordo com as circunstâncias, com as pessoas envolvidas e com os interesses contrapostos nessas interações. O resultado desse processo se expressa por meio de perfis customizados e de postagens que tendem a priorizar aspectos considerados positivos no que diz respeitos aos participantes.

Não obstante o profícuo desenvolvimento desse campo de pesquisa, o qual será revisado e analisado criticamente neste artigo, a literatura especializada apresenta determinadas lacunas a serem preenchidas e desafios a serem elucidados em relação a quais são os possíveis impactos, efeitos ou repercussões que essas redes possam vir a ocasionar na produção de sentidos ou, mais especificamente, na subjetividade de seus usuários. Embora esse tema tenha sido abordado de forma esporádica como, por exemplo, com base na noção de bem-estar (well-being; Chiu, Chenga, Huangb, \& Chen, 2013; Kross et al., 2013), percebe-se carência de investigações sobre essa temática que, em grande parte dos trabalhos, é analisada de forma tangencial ou não é considerada o objeto de estudo propriamente dito.

Assim sendo, o presente estudo objetiva analisar se a literatura acadêmica pode responder aos seguintes questionamentos: quais são as repercussões do fenômeno das redes sociais na produção subjetiva dos usuários? Em que medida a literatura especializada nessa temática pode elucidar esse questionamento, uma vez que se pressupõe que os usuários desenvolvem um processo de negociação de identidades ao utilizarem essas redes? Esses possíveis impactos, efeitos ou repercussões na subjetividade dos usuários são, portanto, o objeto de estudo do presente artigo.

\section{A Metodologia Utilizada: Fontes e Métodos}

Neste estudo, o exame da literatura especializada centrou-se na temática das repercussões do fenômeno redes sociais na subjetividade contemporânea, particularmente, nos estudos e nas pesquisas publicados nos últimos oito anos (de janeiro de 2007 a junho de 2014). Cabe ressalvar que, por estarem imiscuídas no amplo campo de pesquisa da Cibercultura e, frequentemente, atreladas a estudos relacionados a outros ambientes e dispositivos da internet, as investigações sobre as redes sociais, por vezes, pulverizam-se por diversas áreas de concentração ou figuram de forma secundária ou superficial em pesquisas. Por isso, optou-se por estender o período desta revisão para oito anos e por incluir investigações que comparem as redes sociais com os demais dispositivos da internet com o intuito de compreender melhor o atual status da produção científica existente sobre a temática.

As bases de dados bibliográficos acessadas foram a Scientific Eletronic Library Online (SciELO/Pepsico), o banco de teses e de dissertações do Instituto Brasileiro de Ciência e Tecnologia (Ibict), o Portal Periódicos Capes e o Google Acadêmico. Utilizou-se a metodologia do estado da arte, que compreende a avaliação acadêmica e científica de um tema com base na determinação de categorias que identifiquem como um fenômeno vem sendo estudado e analisado. De acordo com Ferreira (2002), as pesquisas bibliográficas têm como objetivo ressaltar a produção de determinadas áreas de conhecimento destacando tendências teóricas e metodológicas. Sendo assim, essa metodologia pode ser conceituada também com base na proposta 
de mapear e de discutir a produção acadêmica sobre uma determinada temática para identificar aspectos e dimensões que têm sido destacados e privilegiados e de efetuar uma análise crítica a respeito.

As seguintes palavras-chave foram pesquisadas em três idiomas (português, inglês e espanhol) nos títulos, nos resumos, nas palavras-chave e, em alguns casos, ao longo dos textos: redes sociais, subjetividade, repercussões, efeitos, impactos e consequências. No que concerne ao critério de inclusão, optou-se pelo uso da noção de repercussão para descrever, de forma abrangente, o que tem sido abordado na literatura como efeitos, como impactos ou como consequências das redes sociais na produção de sentidos ou na produção subjetiva de seus usuários. Embora se esteja ciente das possíveis divergências conceituais, escolheu-se realizar essa aproximação entre esses conceitos devido ao fato de que, na literatura de referência sobre esse tema, eles têm sido utilizados indistintamente para representar o que, neste artigo, compreendem-se como repercussões: as possíveis consequências, os resultados ou as implicações do advento das redes sociais na subjetividade de seus usuários. Assim, reitera-se que, no presente estudo, as referidas definições foram equiparadas durante o levantamento bibliográfico com o objetivo de realizar um mapeamento abrangente dos resultados obtidos no campo da Cibercultura no que se refere às redes sociais.

Nas bases de dados mencionadas e com o levantamento realizado por meio das palavras-chaves definidas, encontraram-se poucos artigos, teses e dissertações que abordam as repercussões das redes sociais na subjetividade como objeto de estudo propriamente dito. Porém, usualmente, esse tema é abordado de forma paralela ou com base em comparações entre outras categorias, como é o caso da identidade. $\mathrm{Na}$ busca desses textos, prevaleceram produções das seguintes áreas: Comunicação Social, Antropologia, Sociologia, Psicologia e Educação. Entre os temas relacionados à temática, aqueles localizados com maior facilidade foram: consumo, identidade e grupos. Para categorizar as tendências teóricas e metodológicas e para analisar os resultados obtidos nas pesquisas, utilizou-se o conceito de indicador (González-Rey, 1999) para referenciar o componente ou o conjunto de elementos manifestos ou latentes que, por meio da interpretação dos pesquisadores, possibilitam a criação de categorias e a interpretação dos processos complexos que envolvem a subjetividade humana. Deste modo, o critério de inclusão dos trabalhos ao longo do corpo do texto se deu com base nos indicadores selecionados e na relevância dos resultados para a apreciação crítica baseada na interpretação desses indicadores.

A definição de subjetividade elencada neste trabalho refere-se à maneira como as pessoas se sentem e pensam com base no que elas vivenciam nas redes, o que abrange os sentidos e os significados atribuídos a essas experiências. Essa noção é oriunda da definição de subjetividade como produto e como produtora de sentidos, tal como propõe González-Rey (2011), a qual se conforma na organização singular do sujeito concreto e nos diferentes níveis da subjetividade social, produzindo sentido para as vivências das pessoas em seus diferentes ambientes.

Com base nessas definições, analisar-se-á como a produção acadêmica e científica acerca das possíveis repercussões do fenômeno das redes sociais na subjetividade contemporânea tem sido estudada e analisada. Ressaltar-se-ão os resultados obtidos e assinalar-se-ão alguns desafios para futuras pesquisas.

\section{A Conformação dos Grupos}

A constituição de grupos no âmbito do $c i$ berespaço chamou a atenção de estudiosos logo ao princípio da configuração das redes sociais, sobretudo, dos sociólogos e jornalistas (Lemos, 2008; Maffesoli, 1987; Rheingold, 1993). A chamada Sociedade em Rede (Castells, 1999a) pressupõe o deslocamento das comunidades para o ambiente virtual da internet e, por conseguinte, para as redes sociais. De tal modo, surgiram não apenas questionamentos sobre quais seriam as implicações desses grupos na sociedade, mas também acerca de como estes podem influenciar a inclusão social; acerca da forma como as pes- 
soas lidam com o espaço público e com as questões de ordem política; acerca do pertencimento às comunidades que se constituem nas redes e que se estendem ao mundo fora delas. Esse movimento de migração para as redes é visto por Frangoso, Rebs e Barth (2011) como a conformação de uma vinculação identitária múltipla e conexa; de experiência multiterritorial constituída pelo vínculo territorial com dois lugares, o físico e o virtual. Desse aporte, pode-se inferir que, embora se tratem de ambientes distintos, com atributos de realidade diferentes, há uma continuidade entre o que ocorre nas redes e fora delas, uma vez que um ambiente se reporta ao outro e vice-versa (Rosa \& Santos, 2013).

Há um consenso entre os pesquisadores de que a continuidade entre os grupos que se constituem dentro e fora das redes é favorável tanto ao desenvolvimento das relações interpessoais, como ao fomento do capital social (Ellison, Steinfield, \& Lampe, 2007; Recuero, 2005). A princípio, houve, por parte dos pesquisadores, certo receio de uma possível substituição dos relacionamentos ditos reais pelos chamados relacionamentos virtuais e de maior isolamento social por parte dos usuários. Contudo, pode-se observar que frequentes interações virtuais auxiliam na manutenção dos relacionamentos já existentes no mundo real e, quando não ocorrem de maneira isolada, tendem a intensificá-los (Nicolaci-da-Costa, 2005b). Neste ponto, vale destacar a possibilidade de inclusão social por meio de redes sociais de internet, processo este que tem sido alcunhado de inclusão digital (Mendonça, 2007) e que pode vir a favorecer segmentos vulneráveis da população como, por exemplo, os portadores de necessidades especiais. Sendo assim, o sentido de pertença surge como novidade no que concerne à produção subjetiva dos usuários, uma vez que as redes, as comunidades e os grupos que se constituem por meio dessas redes prescindem da presença física de seus participantes.

Um dado relevante nesse contexto foi obtido por Fortin e Araújo (2013) e diz respeito a que os usuários vivenciam os dispositivos da internet como um canal libertador e sentem necessidade de navegar, de se comunicar e também de utilizar esses dispositivos com fins sexuais. Mocellin (2007), por seu turno, percebeu que os usuários de redes sociais também se interessam em procurar, em recuperar o passado, buscando encontrar amigos e grupos de muito tempo. Para o autor, essa seria não apenas uma maneira de recuperar antigas amizades, mas também de reformular a própria identidade, tal como propõe Giddens (2002), com base em uma construção fundamentada na apropriação do passado para construir o futuro. Com uma perspectiva similar, Recuero (2008) aponta a vinculação a grupos nas redes como uma forma de declarar e de definir a identidade dos usuários e não somente como uma forma de participar de grupos. Por um lado, com base nos resultados obtidos nessas pesquisas, é nítido que a conformação de novos grupos por afinidades, além de propiciar o compartilhamento de ideias e de vivências, produz certo senso de pertencimento e de identidade entre os usuários. Por outro, retomando a questão das identidades, esses grupos possibilitam também um maior espaço para o desenvolvimento da chamada identidade social (Castells, 1999b). Neste caso, destaca-se o crescente engajamento em manifestações e em movimentos sociais que reivindicam melhoras na vida coletiva. $\mathrm{O}$ ativismo em prol de causas pessoais e sociais passou a ser objeto de pesquisas e motivação a reivindicações coletivas em diferentes países na atualidade (Machado, 2007).

Em detrimento desses indicadores expressivos, um questionamento presente entre usuários e pesquisadores é o seguinte: estariam essas redes tornando as pessoas mais individualistas e solitárias ou mais coletivistas e solidárias? De acordo com Paiva (2012), estabelece-se, nas redes, uma cultura da convergência na qual a individualidade e o narcisismo encontram uma ecologia comunicacional irrigada pela cooperação e pelo compartilhamento. Por isso, segundo o autor, em que pese o fato de que essa comunicação é permeada pela futilidade e pela utilidade individualista e narcisista, é ali onde emerge uma zona de retribalização (Maffesoli, 1987) e de sociabilidade que transcende a dimensão individualista e se conecta com extensões comunitárias. Neste quesito, podemos inferir que a 
participação em redes redimensiona a produção intersubjetiva devido ao fato de que o usuário pode interagir com muitas pessoas ao mesmo tempo. Assim, a profusão de pessoas interagindo simultaneamente é uma novidade em relação aos tempos precursores, nos quais não prescindíamos da presença física imediata.

A comunidade, como um todo, passa a ser representada pelos grupos nesses ambientes virtuais do ciberespaço aos quais os indivíduos têm a possibilidade de pertencer, inclusive, de forma anônima. Sendo assim, cada pessoa pode vir a ter um universo subjetivo oculto e, ao mesmo tempo, partilhado, o qual comparte apenas com determinadas pessoas de sua rede. Vale lembrar que isso já ocorrera no passado. Contudo, hoje, os usuários têm não somente o suporte visual composto por textos, imagens e vídeos para projetar e dar sentido a seu universo subjetivo, mas também outros usuários, anônimos ou não, conhecidos ou não, que se conectam e discutem suas ideias, seus sentimentos e suas aspirações. Há, de fato, uma ampliação do universo intersubjetivo.

Nesse contexto, Gobbi (2010) assinala que as relações interpessoais adquirem maiores proporções em comunidades virtuais, nas quais a confiança e a colaboração permeiam as interações e permitem a sobrevivência de inúmeros grupos em rede. Para ela, este fato dá origem ao conceito de sociabilidade virtual, que, nesta perspectiva, ocorre por meio de grupos e de comunidades que surgem como fator de união que provê meios para inserção social e participação na vida pública e que tendem a favorecer a busca por soluções que tragam benefícios para todos. Contudo, vale lembrar que há grupos e pessoas com propostas escusas que podem cometer crimes por meio das redes sociais, inclusive, que atentam contra os direitos humanos e contra o Estado de Direito. Portanto, atos nocivos ao bem-estar biopsicossocial das pessoas envolvidas e acometidas por estarem conectadas não podem passar despercebidos nesta análise. Um exemplo disto é o caso do chamado cyberbullying que, segundo Rodeghiero (2012), é um tipo de violência que dissemina o preconceito em tom de deboche ou de humor sarcástico provocado pela propagação de um discurso violento de legitima- ção das relações de poder e de domínio e que pode causar sentimentos de raiva, de vergonha, de tristeza e de medo às vítimas. Sendo assim, esse suposto senso de grupo ou de comunidade pode vir a ser acometido pelo seu par oposto, o senso de exclusão e de discriminação.

Diante desses primeiros indicadores que elencamos, é possível afirmar que a literatura demonstra os sensos de pertença, de confiança e de colaboração como os sentidos atribuídos pelos usuários à participação nas redes sociais, tendo o senso de grupo ou de comunidade como uma suposta compreensão partilhada entre os usuários. Não obstante a relevância desses resultados expressivos, cabe a crítica a respeito de como esses sensos podem repercutir na produção de sentidos dos usuários, uma vez que é possível, a estes, utilizar as redes sociais de diferentes maneiras, por motivos variados e com finalidades distintas (Rosa \& Santos, 2014a). Ou seja, cada pessoa pode escolher fazer parte de grupos ou não, interagir com apenas algumas pessoas ou não e até, por exemplo, utilizar as redes para exibir-se ou para observar, voyeuristicamente, os demais sem sequer partilhar desse senso de pertença ou de confiança e de colaboração. Assim, no que concerne à repercussão desse fenômeno das redes sociais na produção subjetiva dos usuários, torna-se frágil a tese do senso de pertença ou de colaboração e de confiança em redes devido às vicissitudes que os tipos de uso, as motivações e as finalidades dos usuários possam vir a ter, tal como especificam Rosa e Santos (2014a). Ademais, se se pensar, por exemplo, na questão do cyberbullying e até do cyberpunk (Lemos, 2008), é possível vislumbrar que os sentidos que os usuários atribuem às atividades nas redes são, muitas vezes, opostos aos de confiança e de colaboração. Em que pese a pertinência desta crítica, é possível evidenciar diversos avanços no campo, sobretudo, na área de concentração designada participação em grupo.

\section{A Expressão e a Estetização do Self dos Usuários}

Com maior preponderância na Sociologia, na Comunicação Social e na Antropologia, há 
pesquisas na área da Cibercultura que seguem a tendência de considerar as possíveis repercussões do fenômeno das redes sociais na subjetividade dos usuários como algo derivado da reprodução e da diversificação do mercado e do consumo em um mundo onde prevalece o capitalismo globalizado. Segundo Sibilia (2008, p. 14), a transição fomentada pelo mercado entre a web 1.0 e a web 2.0 criou um verdadeiro caldeirão de novidades no que diz respeito à nova etapa de desenvolvimento da internet. Sob essa ótica, diferentemente da geração web 1.0, na qual a meta era vender produtos e serviços pela rede, na web 2.0, o objetivo passou a ser a conversão dos usuários em codesenvolvedores de redes, com base na combinação entre o velho slogan "faça você mesmo" e o imperativo "mostre-se como for". Para Sibilia (2008), essa tendência tem alcançado também os demais meios de comunicação e criado maneiras de ser e de conceber-se a si mesmo conforme as mais variadas formas de divulgação da vida íntima.

Nessa mesma tendência e sob perspectiva similar, podemos considerar como referência para este campo de estudo também os desenvolvimentos teóricos de Baudrillard (1999), que concebe o fenômeno da produção subjetiva em redes como a criação de simulações que inibem a troca verdadeira entre seres humanos e produzem certa espectralização da vida por meio de simulacros. Esse ponto de vista, de certa forma, também é compartilhado por Sodré (2002/2013, p. 158) que, por sua vez, pondera sobre a existência de uma apropriação midiática que ele intitulou tecnonarcisismo, entendido como uma dissolução do narcisismo no espelho e cujo ordenamento é considerado artificial e vetorizado pelo universalismo jurídico e pelo mercado. Como consequência, segundo Sodré (2002/2013), há transformações significativas no modo de presença do indivíduo no mundo contemporâneo que, inclusive, podem vir a gerar ilusões para as pessoas que utilizam recursos e ferramentas disponíveis na web, tais como as redes sociais.

Como evidenciam esses primeiros desdobramentos, surge certa tendência cética por detrás dos resultados dessas interações virtuais, cuja produção subjetiva, ampliada por esses meios de comunicação e de informação (Nicolaci-da-Costa, 2005a), passa despercebida e é relegada ao ostracismo por uma suposta incompatibilidade entre o que seria uma transformação nessa produção e uma ilusão ou simulação por esta gerada. Transformação, aqui, traz consigo a ideia de novidade, de novo e, em contrapartida, de ilusão ou de simulação que remete a uma modificação considerada superficial e enfatizante apenas das supostas perdas na produção subjetiva precedente, considerada genuína e proveitosa.

Nesse contexto, a chamada estética de si ou estetização do self (Pinheiro, 2008), que se reflete na exibição de gostos e de estilo de vida nas redes, é vista de maneira ambígua pelos pesquisadores. A alienação de si mesmo, a ilusão referente aos sentidos e os sentimentos que as vivências adquirem para os sujeitos, por um lado, são assinalados como uma possível repercussão das redes na subjetividade contemporânea, a qual acarreta um desprendimento da fantasia e da imaginação e camufla o real (Ferreira-Lemos, 2011). No entanto, por outro lado, a exposição e a publicação de escolhas pelas quais ocorre a autoidentificação nas redes também são consideradas uma oportunidade de comparar, de reconsiderar escolhas já feitas e, portanto, de experimentar, subjetivamente, novas maneiras de ser e de agir (Nicolaci-da-Costa, 2005b). Esta última concepção se baseia na ideia de que há, por parte dos usuários, o intento de conciliar demandas contraditórias e incompatíveis e de distanciarem-se dos riscos inerentes à instabilidade que paira sobre os relacionamentos da vida real, bem como uma expressão transitória da identidade entre todas as suas implicações na época atual (Magalhães \& Paiva, 2009).

Gómez e González (2008) enfatizam o compromisso subjetivo e emocional que os indivíduos destinam a atividades na internet e nas redes sociais como consequência de um possível mal-estar e de uma suposta frustração que o novo repertório tecnológico produz na subjetividade contemporânea. Segundo os autores, por consequência dessa frustração e do desencanto com o consumo que, sob esta ótica, já não propicia satisfação ainda que provenha do imperativo "possuir e ter tudo", ocorre uma inversão do tempo 
real em dedicação a atividades consideradas inúteis ou supérfluas, nas quais as pessoas exercem o consumo por escolhas.

Nessa visão, considera-se que há um mal-estar difuso que acomete as pessoas na contemporaneidade, fazendo com que elas se comuniquem e compartilhem o que expõem nas redes sociais na procura de uma suposta realização plena das necessidades humanas. Segundo Gómez e González (2008), esse sentimento termina por concretizar-se em uma celebração do inútil, do frívolo e do que é superficial. Diante dessa asserção, podemos reiterar que, nessa concepção, parece que as transações entre indivíduos conectados por redes sociais em escala global se reduzem ao supérfluo, ao consumismo, ao hedonismo ou até mesmo a uma decaída da essência da vida e das relações humanas, como bem postula Bauman (2001) com seus conceitos de fluidez e de vida para o consumo. Contudo, ao restringir a nossa visão sobre o fenômeno dessa maneira, estaríamos desconsiderando o fato de que as pessoas não somente interagem e mantêm contatos, mas também reencontram antigos amigos pelas redes ligadas à internet, formam grupos de discussão e de encontros, reforçam o seu capital social (Ellison et al., 2007), divulgam seus trabalhos, expressam-se e buscam saber quem são elas mesmas por meio das redes sociais (Rosa \& Santos, 2014a), entre outras características que demonstram que esse fenômeno é mais amplo do que aparenta ser. Sendo assim, torna-se necessário revisar se essas atividades são realmente supérfluas, ilusórias e consumistas ou se elas contêm ainda outros componentes não observados.

Embora esta crítica traga à baila uma suposta lacuna existente nessa linha de desenvolvimento teórico, a referência a esses estudos pode assinalar que, na área de concentração das pesquisas que enfatiza a dimensão do consumo como potencial causador de repercussões na subjetividade dos usuários, destacam-se dois indicadores relevantes: um que ressalta as repercussões consideradas negativas das redes na subjetividade contemporânea, as quais são descritas tanto por meio de ilusões geradas pela exposição da vida íntima e do consumo por escolhas, como pela perda nas relações humanas ocasionada pela celebração de banalidades, de consumo e de futilidades em redes sociais; outro que enfatiza o compromisso emocional e subjetivo dos usuários para com essas atividades, o que, de fato, sugere que há transformações significativas no modo de presença e no sentido que os indivíduos atribuem às suas atividades no mundo contemporâneo. Sendo assim, esse novo modo de presença e de interação entre sujeitos do mundo contemporâneo é o que suscita ainda mais inquietudes.

Seguindo essa linha de concentração, mas com um viés distinto, há pesquisas que abordam a expressão ou a estetização de si nas redes sociais como um fator prevalente em relação à produção subjetiva. Com base nos postulados teóricos de Turkle (1989) referentes à possibilidade de criação de um eu digital, as pesquisas sobre esse modo de expressão se desenvolveram buscando apreender como as pessoas se apropriam dos recursos e dos dispositivos existentes na internet e, sobretudo, nas redes sociais, para elaborar uma suposta recriação de si mesmas nesses ambientes. Segundo Turkle $(1997,2011)$, a inserção no chamado mundo virtual não altera somente as relações interpessoais, mas também a forma como se é. Nesta perspectiva, propende-se a depositar, cada vez mais, os próprios anseios e frustrações nas novas tecnologias e no mundo virtual e menos em si mesmo, no entorno e no próximo. Ao retornar desse mundo sedutor da tela dos computadores e dos celulares, os indivíduos se tornam mais inseguros nas relações interpessoais e limitados em se sentirem plenos ao estarem em um ambiente ou em outro. Para a autora, as pessoas expõem somente determinados aspectos de suas identidades nesses ambientes virtuais, o que torna a integração desses aspectos problemática devido a que tais aspectos não se encontram totalmente plasmados nem em um ambiente, nem no outro, mas, sim, entre ambos.

Com base nos postulados teóricos de Turkle $(1989,1997,2011)$ referentes à possibilidade de criação de um suposto eu digital, avalia-se que as pesquisas sobre esse modo de expressão se desenvolveram buscando apreender como as pessoas se apropriam dos recursos e dos dispositivos existentes na internet e, sobretudo, nas redes sociais para elaborarem uma suposta re- 
criação de si mesmas nesses ambientes. Nesta perspectiva encontram-se, sobretudo, estudiosos oriundos da Psicologia, da Sociologia e da Comunicação Social. Para descrever e analisar esse fenômeno, são utilizadas, por vezes, expressões como expressão de si mesmo (self expression), apresentação de si mesmo (self presentation), estetização do self, além da categoria de análise identidade.

No Brasil, os trabalhos de Nicolaci-da-Costa $(1998,2005 a)$ e de Recuero $(2008,2009)$ tiveram grande influência no meio acadêmico por demonstrarem, respectivamente: que a expressão de si mesmo em dispositivos como as redes sociais e os desdobramentos procedentes dessa forma de se expressar podem, de fato, ocasionar efeitos na subjetividade dos participantes; que a apropriação e a elaboração pessoal desses espaços virtuais (fotologs e redes sociais) operam como uma produção subjetiva análoga aos diários íntimos, produção essa que adquiriu novas configuração e proporção na atualidade. Com base em uma visão considerada mais positiva em relação a esse fenômeno, a produção acadêmica cresceu em busca de uma compreensão de como essa suposta criação do eu digital, essa expressão ou estetização do self pode ser vivenciada subjetivamente pelos usuários das redes sociais da internet.

De pronto, surgiram algumas controvérsias a respeito de como se dão essa criação do eu digital e suas possíveis consequências. Uma primeira concepção é a de que, ao expor-se e interagir nas redes, os usuários tendem a estetizar ou a elaborar uma configuração identitária que se aproxime das características de identidade almejadas ou socialmente desejadas (Salimkhan, Manago, \& Greenfield, 2010; Zhao et al., 2008). Uma segunda vertente ou linha de pensamento deriva dessa primeira e enfatiza a ideia de que a elaboração de perfis e de seus correlatos equivale a um exercício e a uma experimentação de si mesmo no ambiente virtual e, portanto, reflete características próprias das identidades dos usuários (Fonseca, 2010; Neves \& Portugal, 2011). Sob este último ponto de vista, pressupõe-se que os usuários buscam, nos recursos e nos dispositivos tecnológicos, um modo de experimentar novas formas de ser e até de construir novas identidades nos ambientes virtuais da internet $\mathrm{e}$ em sites de redes sociais.

Nesse contexto, Corredor, Pizón e Gerrero (2011) salientam que estamos diante de uma cultura global cujo descentramento das instituições, do si mesmo e dos sentidos de comunidade tem sido um dos efeitos da globalização e da migração da interação cotidiana para os espaços virtuais. Esses autores destacam, como resultado, a existência de um mundo sem centro no qual ocorre a construção de identidades em meio a complexas negociações estratégicas que as pessoas efetuam para dar coerência à experiência de si e para construir um sentido de comunidade. Carrera (2012), por seu turno, complementa essa noção ao apontar a utilização de fotos como uma maneira de, mediante a corroboração ou a ratificação das pessoas que as visualizam e comentam, dar sentido às identidades e às atividades. Se se pensar em um mundo descentralizado, tal como apontam Carrera (2012) e Corredor et al. (2011), poder-se-ia conjecturar que a maioria dos usuários interage com outras pessoas provenientes de outras cidades e de outros países no cotidiano. Embora isso seja possível e ocorra apenas entre alguns usuários, não se pode deixar de repensar essa questão, pois a experiência demonstra que a interação cotidiana em redes sociais também tende a ocorrer entre grupos restritos, como o grupo de amigos, o que sugere, de certa forma, a circunspecção dessa interação a um limite, mas não inviabiliza que os usuários o ultrapassem.

Não obstante essa provocação e retomando os resultados obtidos pelos autores mencionados, principalmente por Carrera (2012), corrobora-se que essa modalidade de fazer-se presente nas redes sociais servindo-se de fotos e de postagens tem, como matéria-prima, o $h a$ bitus comunicacional e interacional hodierno, que é influenciado pela utilização dos diferentes recursos e dispositivos presentes nesses ambientes. Neste ponto, pode-se enfatizar o antagonismo e, ao mesmo tempo, o entrecruzamento das perspectivas da expressão e da estetização do self dos usuários que, por um lado, enfatizam a influência do mercado e do consumo como fatores alienantes e que, pelo outro lado, destacam 
a expressão, a experimentação ou a estetização do self como aspectos relevantes para a produção subjetiva de sentidos na contemporaneidade. Do resultado dessas correntes divergentes e, ao mesmo tempo, complementares emerge, por conseguinte, um novo olhar que dá lugar ao outro como legitimador do que se posta nas redes sociais. Os usuários estariam, então, imersos em um meio influenciado pelo mercado, no qual eles possuem uma suposta liberdade para se expressar e estetizar o self ou a si mesmos mediante o uso dos recursos e dos dispositivos presentes na rede. Simultaneamente, estariam sujeitos ao crivo dos outros usuários que se conectam e interagem pelas redes sociais.

Com efeito, essa maneira de interagir passou a ser vista entre pesquisadores como uma forma de buscar legitimação do que se pensa, do que se sente e do que se declara como sendo identidade própria com base na opinião do outro (Rosa \& Santos, 2013). Entretanto, Twenge, Konrath, Foster, Campbell e Blushman (2008) apontam um incremento de tendências narcisistas entre usuários, em que pese a função social e utilitária de sites como o Facebook, o que se contrapõe à tese de que as opiniões alheias seriam uma forma preponderante de definir identidades e de buscar legitimação por parte do outro. Nesta visão, a relação com o outro se reproduziria de forma imaginária por meio da elaboração do perfil e das postagens, constituindo-se como uma relação mais do sujeito consigo mesmo do que dele com o outro. A despeito da evidente presença desse incremento das tendências narcisistas, Paiva (2012) assevera que há uma congruência entre o narcisismo e a cultura do compartilhamento, o que torna essa forma de se fazer presente e de interagir nas redes uma maneira não apenas narcísica, mas viabilizadora de uma discussão ainda mais complexa.

Em meio a essas concepções opostas, é sensato inferir que, embora haja uma tendência narcísica de se fazer presente nas redes sociais, de vislumbrar o universo de possibilidades de exibicionismo e de estetização do self nesses recintos, também é recorrente o uso dessas redes para observar, de forma voyeurística, as fotos, as postagens e as interações alheias. Isto é, os usu- ários observam o que ocorre alhures como telespectadores anônimos ou como observadores não participantes. Um exemplo ilustre para esse movimento oposto é o do resultado obtido no estudo realizado por Chou e Edge (2012). Eles detectaram que determinados usuários observavam e percebiam os demais pelo Facebook como mais felizes que eles próprios. Sendo assim, podemos assinalar que essas forças opostas confluem para a expressão de si mesmo ou das identidades dos usuários e, ao mesmo tempo, para a interação e a observação que se estabelecem com os demais utilizadores das redes, conformando-se em um movimento dialético entre o par identidade-alteridade, que se expressa em meio a postagens, a fotos, a comentários e a compartilhamentos.

\section{A Negociação de Identidades nas Redes Sociais}

Rosa e Santos (2013), partindo desses pressupostos, postulam que há um processo de negociação de identidades nos sites de redes sociais que ocorre com base na seleção de traços e de características de identidades expostas ou ocultas por meio da exposição de preferências culturais. Neste ponto de vista, esse processo de expressão ou de estetização de si mesmo advém de maneira recíproca entre os utilizadores que, dependendo das pessoas com quem interagem, tendem a expor ou não determinados traços e características próprias. Assim, para os autores, os usuários se manifestam posicionando-se diante de fatos, de versões, de pessoas e de grupos na medida em que esses posicionamentos possam proporcionar algum tipo de benefício para os sujeitos envolvidos nas interações. Essas manifestações, por um lado, revelam o que os participantes sentem, pensam e desejam, contudo, por outro, dissimulam o que ocorre por detrás das interações.

Em decorrência desse fenômeno e da continuidade das relações interpessoais no ambiente virtual das redes e na vida fora destas, os usuários podem ter, segundo Rosa e Santos (2013), sentimentos positivos e negativos, tais como: segurança-por estabelecer e manter contatos com outras pessoas a distância e também por armazenar dados e registrar atividades -; satisfação e 
felicidade - por se expressar e receber feedbacks a respeito do que posta -; vergonha ou medo de se expor, da violência e de possíveis contradições entre o que é visto nas redes e fora delas - (Rosa \& Santos, 2014b); ciúmes, inveja e raiva - pelo que se vê em relação a si e aos demais.

Os autores mencionados reiteram, contudo, que ainda não há maiores evidências das possíveis repercussões desse processo de negociação de identidades na subjetividade dos usuários das redes sociais. Entretanto, como possíveis consequências negativas, sugerem duas possibilidades. A primeira é o sentimento de dilaceramento que envolve uma situação paradoxal entre o que o indivíduo é e o que deseja ser. A segunda é o sentimento de despedaçamento, pois a possibilidade de sentir-se fragmentado existe devido ao resultado de múltiplas representações e de múltiplos contatos com diversos universos subjetivos que independem dos critérios de tempo e de espaço e das tradições que geram sentidos para as identidades dos indivíduos (Giddens, 2002).

De fato, tal como apontam as pesquisas, pode-se concluir que os resultados dessa modalidade peculiar de expressão e de interação apresentam implicações no que se refere à produção subjetiva contemporânea. Isto é, uma vez que a continuidade entre o que ocorre nas redes sociais e fora delas estabelece-se no dia a dia e a produção subjetiva torna-se descentralizada e tramada em redes, as pessoas ampliam o alcance de seus universos intersubjetivos e a produção de sentidos. Consequentemente, os usuários encontram recursos que podem enaltecer tendências narcísicas e até voyeurísticas, mas buscam também uma legitimação por parte do outro e um sentido para suas identidades e para as atividades que realizam. Porém, ainda não está claro o que há de novo nas possíveis repercussões derivadas da ampliação desse universo intersubjetivo.

Nesse contexto e com base no pressuposto do senso de comunidade em redes gerado entre os chamados mundos real e virtual, percebe-se que os sentidos engendrados nessas interações podem variar e que os sentimentos subsequentes podem ser bons e ruins, conforme a percepção que cada pessoa tenha dessa dinâmica que se estabelece entre o usuário e seus pares, com quem interagem diariamente e intercambiam informações e opiniões, gostos e preferências. Todavia, em que pese a evidência de possíveis repercussões negativas desse fenômeno na produção subjetiva, tais como o senso de exclusão e de discriminação e os sentimentos de dilaceramento ou de fragmentação, ainda não está claro se essas seriam as únicas repercussões e se elas trariam algo de novo à subjetividade de cada usuário das redes sociais, uma vez que se pode questionar se tais reflexos seriam somente uma intensificação do que havia antes.

Como resultado da revisão crítica da bibliografia aqui realizada, concluímos que a literatura especializada abrange, de forma limitada, as questões norteadoras do presente trabalho. No entanto, entre os indicadores mais expressivos das possíveis repercussões das redes na produção subjetiva de seus usuários destacamos, primeiramente, o sentido de canal libertador, a suposta necessidade de navegar, de se comunicar e também de utilizar esses dispositivos com fins sexuais. Em segundo lugar, o senso de comunidade, que deriva em sentidos como o de pertença ou de colaboração e de confiança que possivelmente há entre os usuários. Em terceiro lugar, a expressão ou a estética do si mesmo ou do self, que se manifesta na difusão de gostos e de preferências culturais e na elaboração de perfis, em meio a um processo de negociação de identidades que pode culminar tanto no incremento de tendências narcísicas e voyeurísticas, como na intensificação da busca pela legitimação e pelo reconhecimento por parte do outro ou em sentimentos adversos, como o de dilaceramento e de despedaçamento. Por último, outra repercussão previsível na subjetividade dos usuários é aquela derivada da ampliação do universo intersubjetivo e do contato com culturas distantes geograficamente.

\section{Considerações Finais}

Os resultados evidenciados até o presente momento iluminam o caminho promissor para o desenvolvimento de futuras pesquisas. No entanto, as perguntas norteadoras deste artigo permanecem em aberto. A predominância de 
estudos que ressaltam resultados negativos e até positivos da utilização das redes sociais tende a enclausurar o advento de novas possibilidades interpretativas, limitando o alcance das pesquisas e a compreensão de como esse fenômeno é realmente vivenciado pelos usuários, o que resulta em um ponto cego no que se refere à repercussão das redes sociais na produção subjetiva contemporânea.

Com base nessas evidências, torna-se, portanto, imprescindível explorar ainda mais as possíveis repercussões do fenômeno das redes sociais da internet na subjetividade do homem contemporâneo para que possamos compreender melhor os sentidos que emergem das interações entre usuários conectados em redes em uma escala global. Embora se tenha observado algumas incidências dessas redes no que se refere ao comportamento, aos sentimentos e aos sentidos atribuídos pelos usuários às atividades realizadas nesses ambientes, demonstraram-se, ao longo do texto, algumas lacunas que precisam ser preenchidas para que se avance pelo próspero caminho virtual.

Tendo em vista a possibilidade de que esses indicadores contribuam para a atuação em diferentes âmbitos, tais como o clínico, o social e o educacional, um primeiro desafio é o de analisar ainda mais como se dá essa relação entre o eu e o outro, entre o que é alteridade e identidade nas vivências dos usuários das redes virtuais. Considerando ainda que há um processo de negociação de identidades em um meio onde existem certa liberdade de expressão e enorme profusão de referenciais socioculturais, ademais da influência do mercado e da conformação de diferentes grupos, torna-se relevante apreender melhor como essa aproximação entre indivíduos distantes fisicamente é sentida e como a continuidade entre dentro e fora das redes passa a ser elaborada subjetivamente por esses usuários que expressam ou estetizam o self nas redes. Tal apreensão pode contribuir para que possamos nos apropriar dessas ferramentas e utilizá-las para aprimorar o bem-estar psicossocial das pessoas e promover a melhora do convívio social por meio de programas educativos e preventivos com foco no desenvolvimento pleno da humanidade.
Um segundo desafio pode ser o da compreensão mais abrangente de como essa ampliação da relação intersubjetiva é percebida por usuários de diferentes faixas etárias, gêneros, etnias, nacionalidades e níveis socioeconômicos. Como resultado, mais estudos comparativos das percepções desses usuários podem fornecer subsídios para se repensar a produção subjetiva em um mundo no qual as redes sociais perpassam grande parte das atividades das pessoas que coabitam os conglomerados urbanos, os meios rurais e as populações mais isoladas. Tanto a comparação entre a opinião de duas gerações - a das pessoas que já nasceram em tempos de redes sociais e daquelas que, de certa forma, adaptaram-se e passaram a utilizá-las -, quanto a observação das pessoas que utilizam redes sociais com fins específicos, como, por exemplo, para o trabalho, para o entretenimento e relacionamentos anônimos, como é o caso dos chamados perfis fakes (falsos), podem fornecer dados importantes para análises.

Por último, o elevado nível de informação e a utilização de recursos e de dispositivos para se expressar e interagir nas redes sociais podem repercutir não somente na subjetividade, mas também no desenvolvimento dos processos cognitivos do usuário. Este último aspecto, não abordado neste artigo, pode ser mais uma possibilidade de convergência em pesquisas que, imersas nesse amplo campo de investigação, podem contribuir para o avanço do conhecimento e para a articulação entre a teoria e a prática em diferentes âmbitos. Considerando a exacerbada utilização de celulares, de microcomputadores e de tablets que comportam esses aplicativos, esse pode ser também mais um caminho.

\section{Referências}

Baudrillard, J. (1999). Tela total: Mito-ironias da era do virtual e da imagem (2. ed.). Porto Alegre, RS: Sulina.

Bauman, Z. (2001). Modernidade líquida (P. Dentzein, Trad.). Rio de Janeiro, RJ: Zahar.

Bernardini, G., \& Gobbi, M. C. (2013). Levante popular da juventude brasileira: Saímos do Facebook. Mediação, 15(17), 112-122. 
Boyd, D., \& Ellison, N. (2007). Social network sites: Definition, history and scholarship. Journal of Computer Mediated communication, 113(1). doi:10.1111/j.1083-6101.2007.00393.x

Carrera, F. (2012). Instagram no Facebook: Uma reflexão sobre ethos, consumo e construção de identidades em sites de redes sociais. Animus Revista Interamericana de Comunicação Midiática, 11(22), 148-165. doi:10.5902/217549776850

Castells, M. (1999a). A Era da Informação: Economia, sociedade e cultura: Vol. 1. A sociedade em rede (R. V. Majer, Trad.). São Paulo, SP: Paz e Terra.

Castells, M. (1999b). A Era da Informação: Economia, sociedade e cultura: Vol. 2. O poder da identidade (2. ed., K. B. Gerhardt, Trad.). São Paulo, SP: Paz e Terra.

Chiu, C. M., Chenga, H. L., Huangb, H. Y., \& Chen, C. F. (2013). Exploring individuals' subjective well-being and loyalty towards social network sites from the perspective of network externalities: The Facebook case. International Journal of Information Management, 33, 539-552. doi:10.1016/j.ijinfomgt.2013.01.007

Chou, G. H., \& Edge, N. (2012). They are happier and having better lives than I am: The impact of using Facebook on perceptions of others' lives. Cyberpsychology, Behavior, and Social Networking, 15(2), 117-121. doi:10.1089/cyber.2011.0324

Corredor, J. A., Pizón, O. H., \& Guerrero, R. M. (2011). Mundo sin centro: cultura, construcción de identidad y cognición en la era digital. Revista de Estudios Sociales, 40, 44-56. doi:10.7440/ res40.2011.05

Ellison, N. B., Steinfield, C., \& Lampe, C. (2007). The benefits of Facebook "friends": Social capital and college students' use of online social networks sites. Journal of Computer-Mediated Comunication, 12(7), 1143-1168. doi:10.1111/ j.1083-6101.2007.00367.x

Ferreira, N. S. A. (2002). As pesquisas denominadas "estado da arte". Educação \& Sociedade, 23(79), 257-272.

Ferreira-Lemos, P. P. (2011). Navegar é fantasiar: Relações virtuais e psicanálise. Psico (Porto Alegre), 42(1), 59-66.

Fonseca, C. A. M. (2010). Cartografias do self no Facebook (Dissertação de mestrado em Sociologia,
Universidade de Coimbra, Portugal). Recuperado em https:/estudogeral.sib.uc.pt/jspui/bitstream/10316/14375/1/Tese $\% 20$ Alexandre $\% 20$ Final.pdf

Fortin, I., \& Araújo, C. A. (2013). Aspectos psicológicos do uso patológico da internet. Boletim da Academia Paulista de Psicologia, 33(85), 292311.

Frangoso, S., Rebs, R. R., \& Barth, D. L. (2011). Territorialidades virtuais: Identidade e pertencimento em ambientes multiusuário online. Matrizes, 5(1), 211-225.

Giddens, A. (2002). Modernidade e identidade. Rio de Janeiro, RJ: Jorge Zahar.

Gobbi, M. C. (2010). Nativos digitais: Autores na sociedade tecnológica. In M. C. Gobbi \& M. Kerbauy (Eds.), Televisão digital: Informação e conhecimento (pp. 23-56). São Paulo, SP: Editora da Universidade Estadual Paulista "Júlio de Mesquita Filho". Recuperado em http:// static.scielo.org/scielobooks/k8s27/pdf/gobbi-9788579831010.pdf

Gómez, R., \& González, J. M. (2008). Tecnología y malestar entre jóvenes: la celebración de lo inútil y la emergencia del trabajo liberado. Nómadas, 28, 82-92.

González-Rey, F. L. (1999). La investigación cualitativa en Psicología: rumbos y desafios. São Paulo, SP: Editora da Pontifícia Universidade Católica de São Paulo.

González-Rey, F. L. (2011). Pesquisa qualitativa em Psicologia: Caminhos e desafios. São Paulo, SP: Cengage Learning.

Kross, E., Verduyn, P., Demiralp, E., Park, J., \& Lee, D. S. (2013). Facebook use predicts declines in subjective well-being in young adults. Plos One, 8(8), 69841. doi:10.1371/journal.pone.0069841

Lemos, A. (2008). Cibercultura: Tecnologia e vida social na cultura contemporânea (4. ed.). Porto Alegre, RS: Sulina.

Lemos, A., \& Lévy, P. (2010). O futuro da internet: Em direção a uma ciberdemocracia planetária. Comunicação. São Paulo, SP: Paulus.

Lewis, K., Kaufman, J., Gonzalez, M., Wimmer, A., \& Christakis, N. (2008). Tastes, ties and time: A new social network dataset using Facebook.com. Social Networks, 30, 330-342. doi:10.1016/j.socnet.2008.07.002 
Machado, J. A. S. (2007). Ativismo em rede e conexões identitárias: Novas perspectivas para os movimentos sociais. Sociologias, 9, 18, 248285.

Maffesoli, M. (1987). O tempo das tribos: O declínio do individualismo nas sociedades de massa. Rio de Janeiro, RJ: Forense.

Magalhães, M., \& Paiva, C. C. (2009). Estilos de identidade nas redes sociais de relacionamento. Cultura Midiática, 2(2), 1-9.

Mendonça, A. V. M. (2007). A integração de redes sociais e tecnológicas: Análise do processo de comunicação para inclusão digital (Tese de doutorado em Ciência da Informação, Universidade de Brasília, DF, Brasil).

Mocellin, A. (2007). Internet e identidade: Um estudo sobre o website Orkut. Em Tese, 3(2), 100-121.

Neves, C., \& Portugal, F. T. (2011). A dimensão pública da subjetividade em tempos de Orkut. Psicologia \& Sociedade, 23(1), 15-23.

Nicolaci-da-Costa, A M. (1998). Na malha da rede: Os impactos intimos da rede. Rio de Janeiro, RJ: Campus.

Nicolaci-da-Costa, A. M. (2005a). Primeiros contornos de uma nova "configuração psíquica". $\mathrm{Ca}$ derno Cedes, 25(65), 71-85.

Nicolaci-da-Costa, A. M. (2005b). A sociabilidade virtual: Separando o joio do trigo. Psicologia \& Sociedade, 17(2), 50-57.

Paiva, C. C. (2012). O espírito de Narciso nas águas do Facebook: As redes sociais como extensões do ego e da sociabilidade contemporânea. In Sociedade Brasileira de Estudos Interdisciplinares da Comunicação, XXXV Congresso Brasileiro de Ciências da Comunicação. Recuperado em http://www.intercom.org.br/sis/2012/resumos/ R7-0953-1.pdf

Pinheiro, M. de A. (2008). Subjetivação e consumo em sites de relacionamento. Comunicação, Mídia e Consumo, 5(14), 103-121.

Raleiras, M. S. C. (2009). Identidade, internet e subjetivação: Os sites de redes sociais (Dissertação de mestrado em Ciências da Educação, Universidade de Lisboa, Portugal). Recuperado em http://repositorio.ul.pt/handle/10451/2011

Recuero, R. (2005). O capital social em redes sociais na internet. Famecos, 28, 1-15.
Recuero, R. (2008). Estratégias de personalização e sites de redes sociais: Um estudo de caso da apropriação do fotolog.com. Comunicação, Mídia e Consumo, 5(12), 35-36.

Recuero, R. (2009). Redes sociais na internet. Porto Alegre, RS: Sulina.

Rheingold, H. (1993). The virtual community: Homesteading on the electronic frontier. New York: Harper Collins.

Rodeghiero, C. C. (2012). Violência na internet: Um estudo do cyberbullying no Facebook (Dissertação de mestrado, Programa de Pós-Graduação em Letras, Universidade Católica de Pelotas, RS, Brasil).

Rosa, G. A. M., \& Santos, B. R. (2013). Facebook $e$ as nossas identidades virtuais. Brasília, DF: Thesaurus.

Rosa, G. A. M., \& Santos, B. R. (2014a). Who am I on Facebook? Usage and motivation through user eyes. Psychology Research, 14(1), 60-73.

Rosa, G. A. M., \& Santos, B. R. (2014b). Facebook: Negociação de identidades e o medo da violência. Arquivos Brasileiros de Psicologia, 66(1), 18-32.

Salimkhan, G., Manago, A. M., \& Greenfield, P. M. (2010). The construction of the visual self on MySpace. Cyberpsychology: Journal of Psychosocial Research on Cyberspace, 4(2), Article 1. Retrieved from http://cyberpsychology.eu/view. $\mathrm{php} /$ ?cisloclanku $=2010050203 \&$ article $=1$

Sibilia, P. (2008). O show do eu: A intimidade como espetáculo. Rio de Janeiro, RJ: Nova fronteira.

Sodré, M. (2013). Antropológica do espelho: Uma teoria da comunicação linear e em rede (8. ed.). Petrópolis, RJ: Vozes. (Original publicado em 2002)

Turkle, S. (1989). The second self: Computers and the human spirit. New York: Simon \& Schuster.

Turkle, S. (1997). Life on the screen: Identity in the age of the internet. New York: Simon \& Schuster.

Turkle, S. (2011). Alone together: Why we expect more from technology and less from each other. New York: Basic Books.

Twenge, J. M., Konrath, S., Foster, J. D., Campbell, W. K., \& Blushman, B. J. (2008). Egos infla- 
tion over time: A cross temporal meta-analysis of the narcissistic personality inventory. Journal of Personality, 76, 875-901. doi:10.1111/j.14676494.2008.00507.x

Watts, D. J. (2004). The "new" science of networks. Annual Review of Sociology, 30, 243-270. doi:10.1146/annurev.soc.30.020404

Watts, D. J. (2007). A twenty-first century science. Nature, 445, 449. doi:10.1038/445489a
Zhao, S., Grasmuck, S., \& Martin, J. (2008). Identity construction on Facebook: Digital empowerment in anchored relationships. Computer in $\mathrm{Hu}$ man Behavior, 24(5), 1816-1836. doi:10.1016/j. chb.2008.02.012
Recebido: 17/07/2014

$1^{a}$ revisão: 02/10/2014 Aceite final: 27/10/2014 